\title{
Mariella Colin (dir.), Les catéchismes et les littératures chrétiennes pour l'enfance en Europe $\left(\mathrm{XVI}^{\mathrm{e}}-\mathrm{XXI}^{\mathrm{e}}\right.$ siècle)
}

Pessac, Presses universitaires de Bordeaux, coll. « Études sur le livre de jeunesse », 2014, $324 \mathrm{p}$.

Jean-Bruno Renard

\section{(2) OpenEdition}

Journals

Édition électronique

URL : http://journals.openedition.org/assr/28216

DOI : $10.4000 /$ assr.28216

ISSN : $1777-5825$

Éditeur

Éditions de l'EHESS

Édition imprimée

Date de publication : 31 décembre 2016

Pagination : 294

ISSN : 0335-5985

\section{Référence électronique}

Jean-Bruno Renard, « Mariella Colin (dir.), Les catéchismes et les littératures chrétiennes pour l'enfance en Europe ( $\mathrm{xvI}^{\mathrm{e}}-\mathrm{xxl} \mathrm{l}^{\mathrm{e}}$ siècle) », Archives de sciences sociales des religions [En ligne], 176। octobre-décembre 2016, mis en ligne le 17 juillet 2017, consulté le 24 septembre 2020. URL : http:// journals.openedition.org/assr/28216; DOI : https://doi.org/10.4000/assr.28216 


\section{Mariella Colin (dir.), Les catéchismes et les littératures chrétiennes pour l'enfance en Europe ( $\mathrm{XVI}^{\mathrm{e}}-\mathrm{XXI}^{\mathrm{e}}$ siècle)}

Pessac, Presses universitaires de Bordeaux, coll. « Études sur le livre de jeunesse », 2014, $324 \mathrm{p}$.

Jean-Bruno Renard

\section{RÉFÉRENCE}

Mariella Colin (dir.), Les catéchismes et les littératures chrétiennes pour l'enfance en

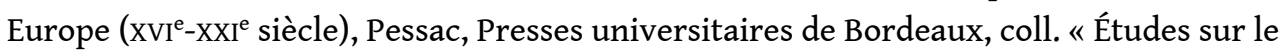
livre de jeunesse », 2014, $324 \mathrm{p}$.

1 On ne saurait demander à des actes de colloque le traitement exhaustif d'un sujet. Mais le signataire de la présente recension ne peut s'empêcher de regretter la quasi-absence dans cet ouvrage de la Bande dessinée chrétienne, domaine pourtant bien balisé, notamment grâce au frère Roland Francart ( $L a$ BD chrétienne, Éditions du Cerf, 1994). Bien qu'éclatées en deux types de productions éditoriales sensiblement différents - les catéchismes d'une part, la littérature chrétienne d'autre part - et en de multiples objets d'études assez pointus, les contributions rassemblées ici apportent des aperçus érudits sur les livres chrétiens pour la jeunesse, en Europe, du XVI ${ }^{\mathrm{e}}$ au xxI siècle.

La première partie ( Catéchismes pour l'enfance en Europe ») s'ouvre avec un texte de Philippe Martin sur l'histoire du catéchisme en France, de sa naissance au xve siècle jusqu'à nos jours. Jean-Marie Paul présente les deux catéchismes de Luther, le Petit Catéchisme (1528) et le Grand Catéchisme (1529), dont le statut diffère des catéchismes catholiques en ce qu'ils jouent " un rôle fondateur qui dépasse la simple transmission d'une doctrine consacrée » (p. 52). Marco Cavarzere montre que le concile de Trente, au 
milieu du XvI $\mathrm{e}^{\mathrm{e}}$ siècle, est à l'origine des catéchismes catholiques de l'époque moderne. En Espagne, comme le souligne Manuela Águeda Garcia-Garrido, le catéchisme du jésuite Gaspar Astete, publié dans les années 1590, a occupé une place centrale dans l'instruction religieuse de la jeunesse. Éric Leroy du Cardonnoy consacre sa contribution au chanoine allemand Christoph von Schmid, auteur entre 1810 et 1845 de plusieurs catéchismes qui ont accompagné le renouveau de la vie spirituelle catholique dans les pays germaniques. Stéphanie Anne Delcroix étudie les catéchismes du diocèse francophone de Malines, en Belgique, de 1843 à 1918, en montrant l'évolution de leur contenu et de leur forme. Les deux derniers textes de cette première partie traitent des catéchismes orthodoxes russes : Antoine Nivière en retrace l'histoire, $\mathrm{du} \mathrm{xVII}^{\mathrm{e}}$ au début $\mathrm{du} \mathrm{xx}^{\mathrm{e}}$ siècle, tandis qu'Irène Semenoff-Tian-Chansky-Baïdine explique pourquoi les catéchismes en usage aujourd'hui en Russie sont ceux de l'émigration, diffusant une appartenance identitaire en même temps que l'enseignement de la foi.

3 La seconde partie de l'ouvrage («Littératures chrétiennes pour l'enfance en Europe ») présente des études de cas variées sur des maisons d'édition et des écrivains qui ont œuvré depuis le XIX ${ }^{\mathrm{e}}$ siècle à la production d'une littérature chrétienne ou d'inspiration chrétienne destinée à la jeunesse. Cécile Boulaire retrace l'aventure des éditions Mame, prestigieuse maison d'édition catholique créée à Tours en 1836 et toujours en activité. Bernard Jahier sort de l'oubli un «best-seller du catholicisme triomphant » (p. 167), Le Journal de Marguerite (1858), qui fut réédité jusqu'en 1929 et marqua des générations de petites filles catholiques. Mathilde Lévêque montre comment, dans les années 1840 et 1850, la traduction en français des récits pour la jeunesse de l'Allemande Amalia Schoppe a été mise au service de l'idéologie catholique. Sara Thornton nous fait découvrir une curiosité littéraire peu connue : un texte de Charles Dickens, The Life of Our Lord, ouvrage privé écrit entre 1846 et 1849 par le célèbre écrivain britannique pour ses enfants, auxquels il racontait le soir la vie de Jésus. Mariella Colin s'intéresse à l'œuvre de don Bosco - saint Jean Bosco pour les Français - qui écrivit plusieurs biographies édifiantes d'enfants saints dans la seconde moitié du xix siècle. Francesca Pizzigoni présente une maison d'édition catholique italienne pour enfants, la SEI (Società Editrice Internazionale), fondée à Turin en 1923 et chantre d'une morale catholique aujourd'hui datée. Marie Franco étudie le livre Le Cuaderno de Celia - Primera comunión (Le Cahier de Celia - Première communion), publié en 1947 par Elena Fortún, prolifique auteur pour la jeunesse. Elle y voit un ouvrage emblématique de l'éducation de la jeunesse dans l'Espagne franquiste. La figure de sainte Thérèse d'Avila, comme le montre Nicolas Mollard, a donné lieu en Espagne à une centaine d'ouvrages biographiques, visant plus particulièrement un public jeune. En France, rappelle Béatrice Finet, c'est une autre sainte Thérèse qui est racontée aux enfants : Thérèse de Lisieux. L'ouvrage se clôt avec la contribution de Virginie Douglas, qui donne un aperçu sur " la religion dans les romans britanniques pour la jeunesse de 1945 à nos jours ", une thématique toujours prégnante, qu'elle soit traitée de manière plutôt conservatrice ou plutôt subversive.

4 Publié avec beaucoup de soin et doté de nombreuses références en bas de page, cet ouvrage est destiné à tous les chercheurs qui s'intéressent aux « diverses manières de transmettre par les livres la doctrine religieuse aux enfants, [...] en s'interrogeant sur les stratégies, les formes et les genres », ainsi que l'écrit Mariella Colin dans son «Introduction» (p. 7). 